\title{
Additional study of the morphology of eggs and miracidia of Eurytrema coelomaticum (Trematoda)
}

\author{
J. PINHEIRO 1,*, D. O. FRANCO-ACUÑA ${ }^{2}$, A. OLIVEIRA-MENEZES ${ }^{3}$, S. V. P. B. BRANDOLINI', F. A. O. ADNET ${ }^{5}$, \\ E. J. LOPES TORRES ${ }^{6}$, F. J. B. MIRANDA ${ }^{7}$, W. DE SOUZA ${ }^{8}$, R. A. DAMATTA ${ }^{7}$
}

\begin{abstract}
1,*Área de Biofísica, Departamento de Ciências Fisiológicas, Instituto de Biologia, UFRRJ, Seropédica, RJ, Brazil, E-mail: jps@ufrrj.br, ${ }^{2}$ Curso de Pós-Graduação em Ciências Veterinárias, Departamento de Parasitologia Animal, Instituto de Veterinária, UFRRJ, Seropédica, RJ. Secretaria Municipal de Educação do Rio de Janeiro, Prefeitura da Cidade do Rio de Janeiro, Rio de Janeiro, RJ, Brazil; ${ }^{3}$ Pólo Cidade Universitária, Campus Universidade Federal do Rio de Janeiro, Macaé, Av. Aluizio da Silva Gomes, 50, Granja dos Cavaleiros, Macaé, RJ, Brazil; ${ }^{4}$ Área de Biologia, Departamento de Biologia Animal, Instituto de Biologia,

UFRRJ, Seropédica, RJ, Brazil; ${ }^{5}$ Curso de Pós-Graduação em Biofísica, Laboratório de Biologia de Helmintos Otto Wucherer, Programa de Biologia Celular e Parasitologia, Instituto de Biofísica Carlos Chagas Filho, Centro de Ciências da Saúde, UFRJ, Rio de Janeiro, RJ, Brazil; ${ }^{6}$ Laboratório de Helmintologia Romero Lascasas Porto, Departamento de Microbiologia, Imunologia e Parasitologia da Faculdade de Ciências Médicas, UERJ, RJ, Brazil; ${ }^{7}$ Laboratório de Biologia Celular e Tecidual, Centro de Biologia e Biotecnologia, UENF, Campos dos Goytacazes, RJ, Brazil; ${ }^{8}$ Laboratório de Ultraestrura Celular Hertha Meyer, Programa de Biologia Celular e

Parasitologia, Instituto de Biofísica Carlos Chagas Filho, Centro de Ciências da Saúde, UFRJ, Rio de Janeiro, RJ, Brazil
\end{abstract}

\section{Article info}

Received January 15, 2015 Accepted March 12, 2015

\begin{abstract}
Summary
The morphology of the eggs and miracidia of Eurytrema coelomaticum was analyzed. The eggshell presented different composition according to the maturation stage of the egg, as seen by distinct birefringence after polarized light microscopic analysis. Detailed morphology of the brownish eggs, measuring $44.97 \pm 3.83(38.67-51.40) \mu \mathrm{m}$ in length and 30.71 $\pm 2.54(25.79-34.47) \mu \mathrm{m}$ in width, and the different electrondensities of the inner, middle and outer layers of the eggs were determined using light (bright field and DIC) and electronic microscopy (scanning and transmission). The morphometry of the eggs is in accordance to those measures presented in previous studies. The miracidia were observed using light microscopy, inside and outside the egg. It was possible to observe the terebratorium at the anterior end of the body, the ciliated epidermal plates, placed according the formula $E=2 E_{1}+2 E_{2}$, and the interepidermal ridge, but eyespots were not observed. The excretory vesicle was laterally placed in the posterior middle of the body and the germ balls were observed. The miracidium inside the egg was observed by routine techniques, but the miracidium was not well preserved. Thus, the eggs were processed using high pressure-freeze substitution technique and reasonable preservation was achieved. The cilia covering the larval body, with a typical ciliary organization, the terebratorium with folds and the junction of the epidermal ciliated cell with the larval body were seen. For the first time detailed information on the eggs and miracidia of $E$. coelomaticum is given, which can be the basis for new studies.
\end{abstract}

Keywords: Digenea; larval trematode; high pressure freezing; light microscopy; Eurytrema coelomaticum

\section{Introduction}

Eurytrema coelomaticum (Giard et Billet, 1892) Looss, 1907 is a digenetic trematode found in Brazil and in some Asian countries. In spite of its economic and veterinary importance, it is poorly studied (Bassani et al., 2006; llha et al., 2005). The Eurytrema species are found in Europe, Asia and South America and commonly parasitize the pancreatic ducts of ruminants, particularly affecting cattle, causing economic losses due to reduced meat and milk production.

Since the description of E. coelomaticum, only Tang and Tang (1977) have reported the biology and epidemiology of this species, presenting drawings of the larval stages during the life cycle of this trematode. Brandolini and Amato (2001) showed the larval 
development of $E$. coelomaticum in the snail host, using histological techniques. But new descriptions of the morphology and ultrastructure of the intramolluscan larval stages of this parasite were only published many years after its description (Franco-Acuña et al., 2011; Pinheiro et al., 2011; 2012).

During E. coelomaticum's life cycle, the adult worms release mature eggs in the pancreatic ducts, from where they are carried to the intestine with pancreatic secretions and eliminated with the feces. The eggs, each with one fully developed miracidium, remain in the external environment until being ingested by the snail host Bradybaena similaris, where the larval intramolluscan development begins. In the external environment the eggs must protect the enclosed larvae to ensure their viability and ability to enter the first intermediate host and establish infection. The eggs of helminth parasites are also important elements to diagnose patent infections by parasitological examination of feces. For the best-known species, such as Fasciola hepatica and Schistosoma mansoni, many studies have been performed on the structure of the fluke eggs (Wilson, 1967; Race, 1969; Irwin and Threadgold, 1972; Koie et al., 1976). Travassos (1944) reported the dimensions of $E$. coelomaticum eggs $(50-42 \mu \mathrm{m}$ length and $23-30 \mu \mathrm{m}$ width). Tang (1950) did the same for E. pancreaticum eggs (55 $41 \mu \mathrm{m}$ length and $38-28 \mu \mathrm{m}$ width). Travassos (1944) also stated that mature eggs are dark brown and thick shelled, while immature ones are lighter in color.

While it is possible to find some studies of $E$. coelomaticum eggs, the miracidia were only cited by Tang and Tang (1977), when they described the establishment of the infection in the snail host. These authors presented a single drawing of the miracidium, but they did not describe its morphology. Thus, this larval stage of $E$. coelomaticum is largely unknown.

The present study aimed to clarify some points of the morphology of the eggs and miracidia, using light (bright field, polarized light and DIC), scanning and transmission electron microscopy, since the previous studies only contain drawings of these stages and further elucidation of some points is needed.

\section{Materials and Methods}

\section{Collection of E. coelomaticum and obtaining eggs}

The adult worms were collected from the pancreas of naturally infected cattle that had been slaughtered in an industrial abattoir (Matadouro Municipal de Barra Mansa, Barra Mansa, RJ, Brazil). The adult worms were kept overnight in Petri dishes with Locke's saline solution (Humason, 1979). Adult worms were discarded and eggs were sedimented. The eggs were washed three times in Locke's saline solution and stored at $10^{\circ} \mathrm{C}$ until examination. Adult worms of each collection were randomly sampled, processed according to Amato et al. (1990) and identified as E. coelomaticum according to Yamaguti (1971).

\section{Light microscopy}

For light microscopy (LM), fresh eggs with miracidia inside were randomly chosen and transferred to glass slides with the saline solution as medium and observed by bright field, DIC and polarized light microscopy, and 133 eggs were measured. The eggs and miracidia were observed and measured using an Olympus BX51 light microscope, and the images were captured with an MRc5 AxioCam digital camera and processed with the Axiovision program. The measures are presented as mean and standard deviation with the minimum and maximum in parentheses.

After observation of the fresh eggs, slight pressure was applied on each cover slips to open the egg and force the miracidium out. The miracidia were impregnated with $0.15 \%$ aqueous silver nitrate according to Amato et al. (1991), and their epidermal ciliated plates were analyzed under the light microscope $(n=34)$.

\section{Scanning and transmission electron microscopy of eggs}

For scanning electron microscopy (SEM), the eggs were fixed in $2.5 \%$ glutaraldehyde in $0.1 \mathrm{M}$ cacodylate buffer, $\mathrm{pH}$ 7.4. The fixed larvae were washed three times in $0.1 \mathrm{M}$ cacodylate buffer, $\mathrm{pH}$ 7.4 , post fixed in $1 \%$ osmium tetroxide and $0.8 \%$ potassium ferricyanide, and washed again in the same buffer. The larvae were dehydrated in a crescent ethanol series and critical-point dried using $\mathrm{CO}_{2}$ (Baltec CPD). In some experiments, the dried specimens were mechanically fractured. The sporocysts were mounted on metallic stubs and gold coated (Pinheiro et al., 2011). The observations were made using a Zeiss DSM962 or a Jeol SEM5310 scanning electron microscope, operating at $20 \mathrm{kV}$. The images were obtained using the SemAfore software.

For transmission electron microscopy (TEM), fresh eggs were fixed in $2.5 \%$ glutaraldehyde in $0.1 \mathrm{M}$ cacodylate buffer, $\mathrm{pH} 7.4$ for $24 \mathrm{~h}$. The fixed eggs were washed in $0.1 \mathrm{M}$ cacodylate buffer, post fixed in $1 \%$ osmium tetroxide and $0.8 \%$ ferrocyanide, washed again in the same buffer, dehydrated in a crescent series of acetone and then infiltrated and embedded in epoxy resin (Polybed). Semi-thin sections were stained with toluidine blue and observed under the light microscope. Ultrathin sections were stained with uranyl acetate and lead citrate (De Souza, 2007) and observed with a Zeiss 900 transmission electron microscope at $80 \mathrm{kV}$. This procedure did not preserve the miracidia inside the eggs, and it was not possible to obtain images of the larvae. For this reason, the eggs with miracidia were processed as described below.

Alternatively, for TEM the fresh eggs, with live miracidia enclosed, were sandwiched in aluminum carriers $(3 \times 0.5 \mathrm{~mm})$ (Leica Microsystems, Vienna, Austria). The sandwiched samples were mounted in the high-pressure freezing (HPF) holder and frozen using a Bal-Tec HPM 010 HPF machine (Bal-Tec, Corp., Liechtenstein). After freezing, the samples were transferred immediately to liquid nitrogen, in which they were maintained until required for further processing. Samples were immersed in a substitution medium consisting of $2 \%$ ( vol $/ \mathrm{vol}$ ) osmium tetroxide, $0.1 \%$ (vol/vol) glutaraldehyde and $1 \%$ (vol/vol) water in acetone, pre-cooled to $-90^{\circ} \mathrm{C}$ using a Leica EMP apparatus (Leica Microsystems, Vienna, Austria). The samples were kept at $-80^{\circ} \mathrm{C}$ for $72 \mathrm{~h}$, then warmed to $-20^{\circ} \mathrm{C}$ for $15 \mathrm{~h}$ and maintained at $4{ }^{\circ} \mathrm{C}$ for $2 \mathrm{~h}$ (Girard-Dias et al., 2012). After substitution, the samples were washed three times with acetone at room temperature and then stepwise embedded in epoxy resin (Polybed) and polymerized using a microwave oven. Ultrathin sections were stained with uranyl acetate and lead citrate (De Souza 2007) and observed under a Zeiss 900 transmission electron microscope at $80 \mathrm{kV}$. The images were obtained using the iTEM software. 


\section{Results}

\section{Eggs}

The eggs of $E$. coelomaticum in different developmental stages were observed using LM, and displayed a brownish or yellowish color and an elongated shape. These eggs did not contain miracidia (Figs. 1a and e), while the mature eggs were brownish and each contained a single fully developed miracidium (Figs. 1c and f). The observation using polarized light showed different birefringence of the immature (Fig. 1b) and mature eggs (Fig. 1d). Only the brownish eggs were used in the morphological studies. The operculum was evident at the anterior end of the eggshell (Fig. 1e) and it detached when slight pressure was applied on the coverslip, releasing the egg content (Fig. 2a). SEM revealed grouped or isolated eggs (Figs. 2b and c) and the operculum was well delimited, as seen in lateral and upper views (Figs. $2 \mathrm{~b}$ and $\mathrm{c}$ ). The eggshell did not present specializations, like spines or projections (Figs. 2a and c). The eggs measured $44.97 \pm 3.83(38.67-51.40) \mu \mathrm{m}$ in length and $30.71 \pm 2.54(25.79-34.47) \mu \mathrm{m}$ in width.

The ultrathin sections evidenced the eggshell and a decomposed miracidium inside (Fig. 2d). The eggshell is thick, $3.70 \pm 0.56 \mu \mathrm{m}$ $(3.3-4.1)$ at the anterior and posterior ends and $2.32 \pm 0.43 \mu \mathrm{m}$ $(1.8-2.8)$ laterally. It was possible to distinguish three different regions of the shell: the inner and outer surfaces, both very thin and more electron-dense, and the middle, less electron-dense heterogeneous layer, composing the major part (Fig. 2e). It was possible to observe the region of the operculum insertion in the egg (Fig. 2f), showing no specialization or any other detail on the contact surface between operculum and shell.

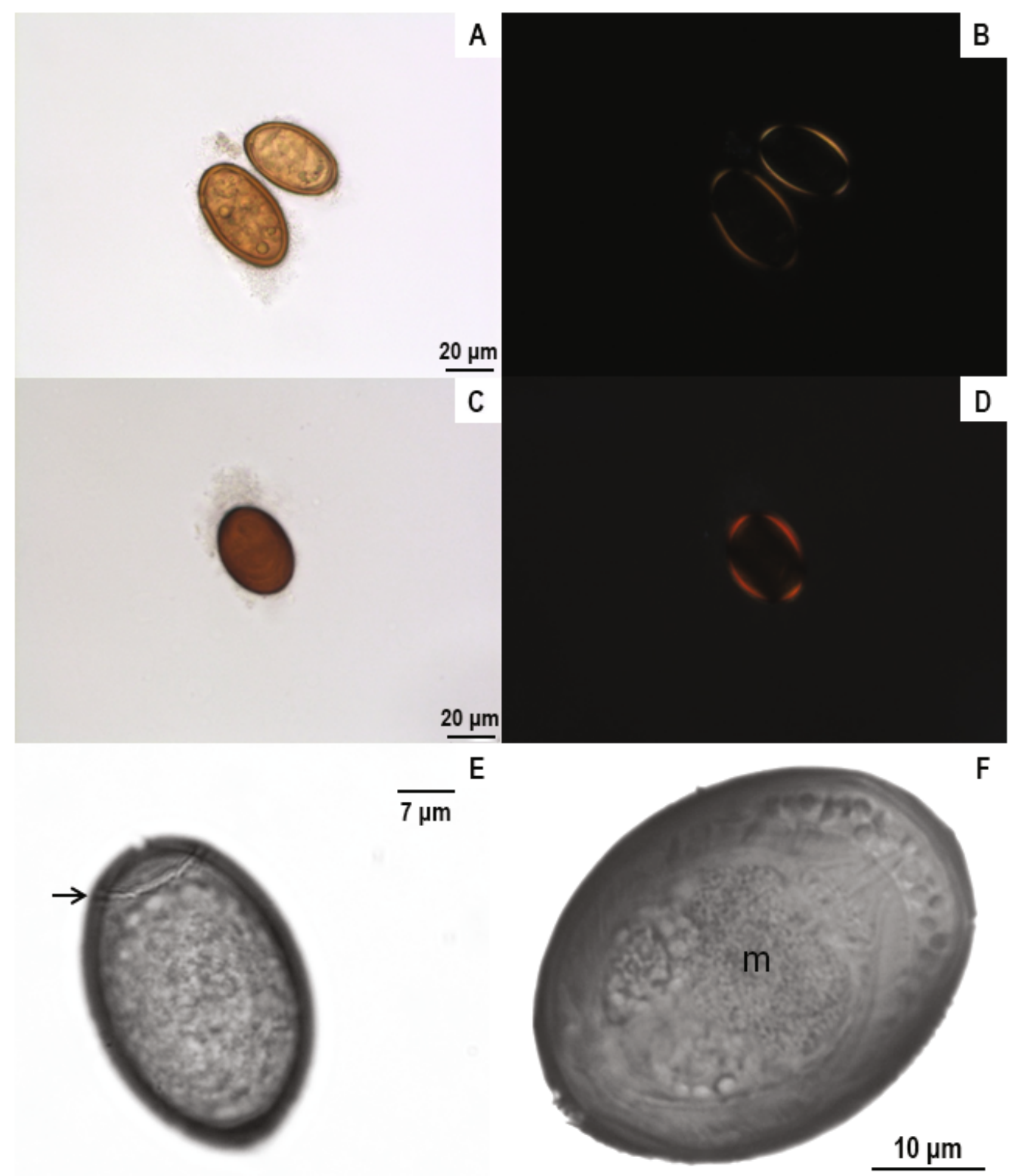

Fig. 1. Light microscopy (LM) of Eurytrema coelomaticum eggs. a - Immature eggs, brow yellow color; $b$ - Birefringence of immature eggs; c - Mature egg, brown color; d - Birefringence of mature egg; e - Immature egg showing the operculum at the anterior end (arrow); $\mathrm{f}-$ Mature egg with a fully developed miracidium inside it $(\mathrm{m})$ 


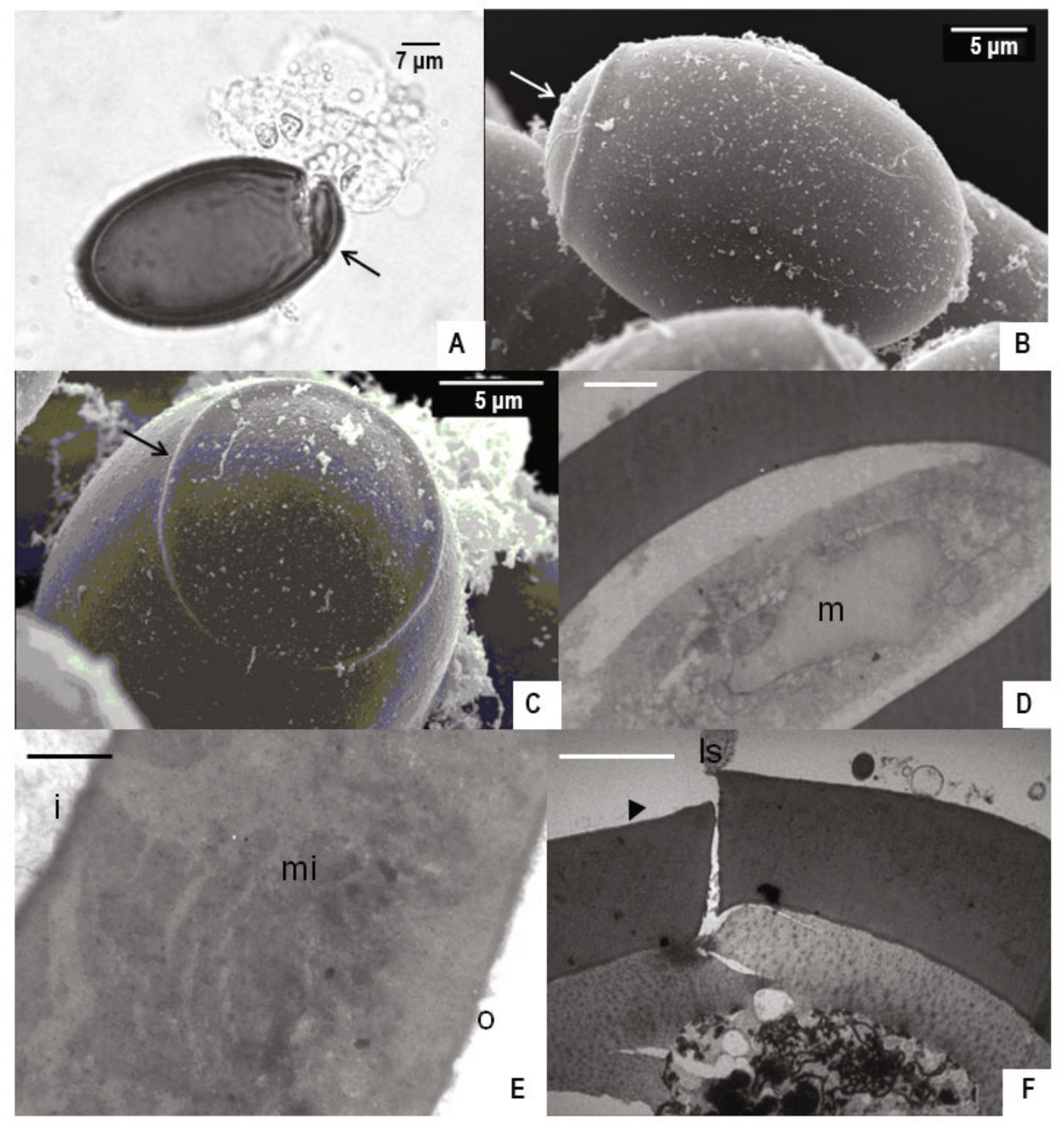

Fig. 2. Eggs of Eurytrema coelomaticum. a - LM of the eggs showing the detachment of the operculum when the egg was opened; $b$ - Lateral view of the egg, observed by scanning electron microscopy (SEM), showing the operculum at the anterior region; $c-$ Upper view of the egg showing the anterior region where the operculum is located by SEM; $d$ - Transmission electron microscopy (TEM) of the entire egg with a decomposed miracidium $(\mathrm{m}$ ) inside it. Scale bar=2 $\mu \mathrm{m} ; \mathrm{e}-\mathrm{TEM}$ showing a detailed view of the eggshell with the inner (i) and outer (o) layer more electrondense and the middle layer (mi) less electrondense than the other two. Scale bar=500 $\mathrm{nm} ; \mathrm{f}-$ Detailed view by TEM of the eggshell (arrowhead) in the operculum region showing the line suture (Is). Scale bar $=2 \mu \mathrm{m}$

\section{Miracidium}

It was possible observe the precise moment of the miracidium's exit from the egg, by placing slight pressure on it (Fig. 3a). When these miracidium was silver nitrate impregnated, it was possible to observe the delimitation of one epidermal ciliated plate (Fig. 3b). When the miracidium was entirely out of the eggshell, it presented an elongated shape, in the anterior-posterior direction (Fig. 3c), with one interepidermal ridge in the anterior row (Fig. 3d). In miracidium out of the egg it was also possible to observe an excretory vesicle, which determined the frontal position of the larva, and the excretory vesicles opened in a lateral aperture of the body.

In another view, the miracidium appears peach shaped (Fig. 3d), with the terebratorium located in the anterior end (Fig. 3a and c). The larval body is covered by cilia. The excretory system is located in the posterior middle of the miracidial body, with the excretory vesicles having apertures located in the interepidermal space between the first and second interepidermal ridges (Fig. 3d) and the germinal cells (Fig. 3d). These observations allow us to propose the existence of two rows of epidermal ciliated plates, one anterior composed of two cells in a ventrodorsolateral (VDL) position, and 
a second row in the posterior region of the body, also composed of two epidermal ciliated plates in the same position. Thus, it is possible to propose the following, using the nomenclature described by Dimitrov et al. (1995):

$$
\begin{array}{ll}
E=2 E_{1}+2 E_{2} \quad & E_{1}=1+1 E_{1} V D L \\
& E_{2}=1+1 E_{2} V D L
\end{array}
$$

TEM after routine processing technique showed the miracidium inside the egg always partially decomposed, due to the difficult penetration of the fixative (Fig. 4a), but in the well-preserved larvae it was possible to observe the cilia of the epidermal ciliated plates covering the larval body, but the interepidermal ridge was not seen (Fig. 4b). The point where the anterior epidermal ciliated plate is attached to the miracidium body was observed (Fig. 4c) with an image of two adjacent membranes, forming a septate junction. At the anterior end, the terebratorium presented the penetration gland with a space, probably occupied by the products of the penetration gland, used by the larva to penetrate in the digestive sys- tem of the host snail (Fig. 4c). In addition, in this region there were folds in the tegument, increasing the contact surface and favoring the adhesion of the larva to the body of the intermediate host snail when the penetration occurs in its intestine. Figure $4 \mathrm{~d}$ shows a detail of the cilia, revealing a typical ciliary organization with axis, basal body and root, at an angle near $90^{\circ}$ in relation to the axis.

\section{Discussion}

The shape and color of the eggs were similar to previous reports in the literature (Tang, 1950; Tang and Tang, 1977), but for the first time the different birefringence of the eggs according to their developmental stage was observed. This difference may be related to the distinct stage of tannin impregnation, with the immature eggs being poor and the mature ones rich in tannin. The presence of tannin in the eggshell of trematodes gives them their brownish color and is probably responsible for the different birefringence observed here in $E$. coelomaticum eggs.

For a long time it was thought that the Mehlis gland provided the

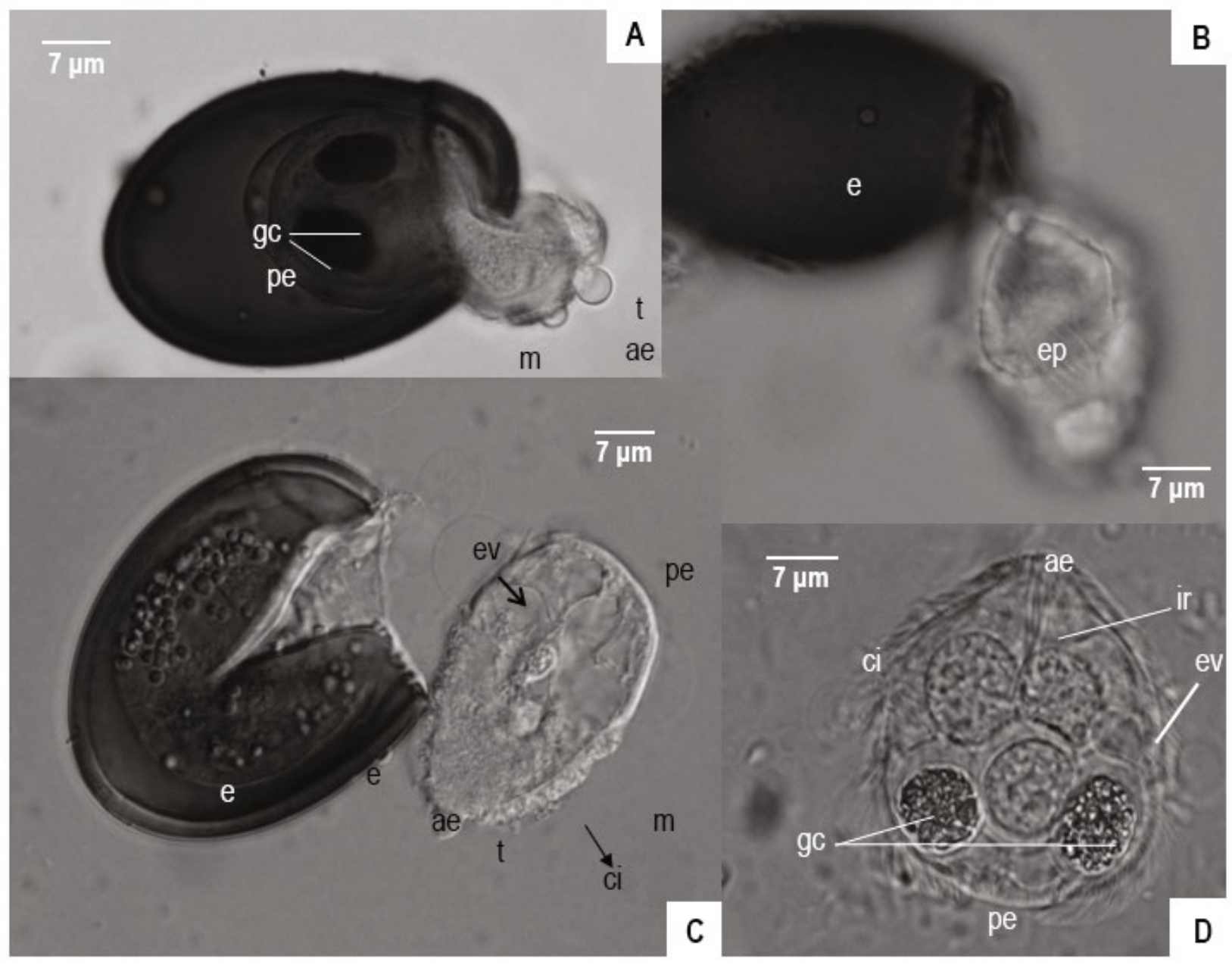

Fig. 3. LM of the miracidium of Eurytrema coelomaticum. a - LM, bright field, of the precise moment of the operculum aperture with the exit of a miracidium ( $\mathrm{m}$ ) from the egg, showing the anterior end (ae) of the larva, with terebratorium (t) out of the egg and the posterior end (pe) with the germ balls (gc); b- LM, bright field, of the miracidium hatched after silver nitrate impregnation showing the contour of an epidermal ciliated plate (ep) at the posterior region of the body. e=egg; $\mathrm{C}-\mathrm{LM}$, DIC, of a miracidium ( $\mathrm{m}$ ) entirely out of the egg after mechanical pressure on the coverslip, showing the cilia (ci) of the epidermal ciliated plates (cells), the terebratorium ( $\mathrm{t}$ ) without cilia, and one excretory vesicle (ev) at the posterior region of the body (ae=anterior end, pe=posterior end); $\mathrm{d}-\mathrm{LM}$, DIC, of a free miracidium showing the cilia

(ci), the interepidermic ridge (ir) between the anterior ciliated epidermic cells, and the excretory vesicle (ev) laterally located in the posterior middle of the body and the germ balls ( $\mathrm{gc}$ ) 


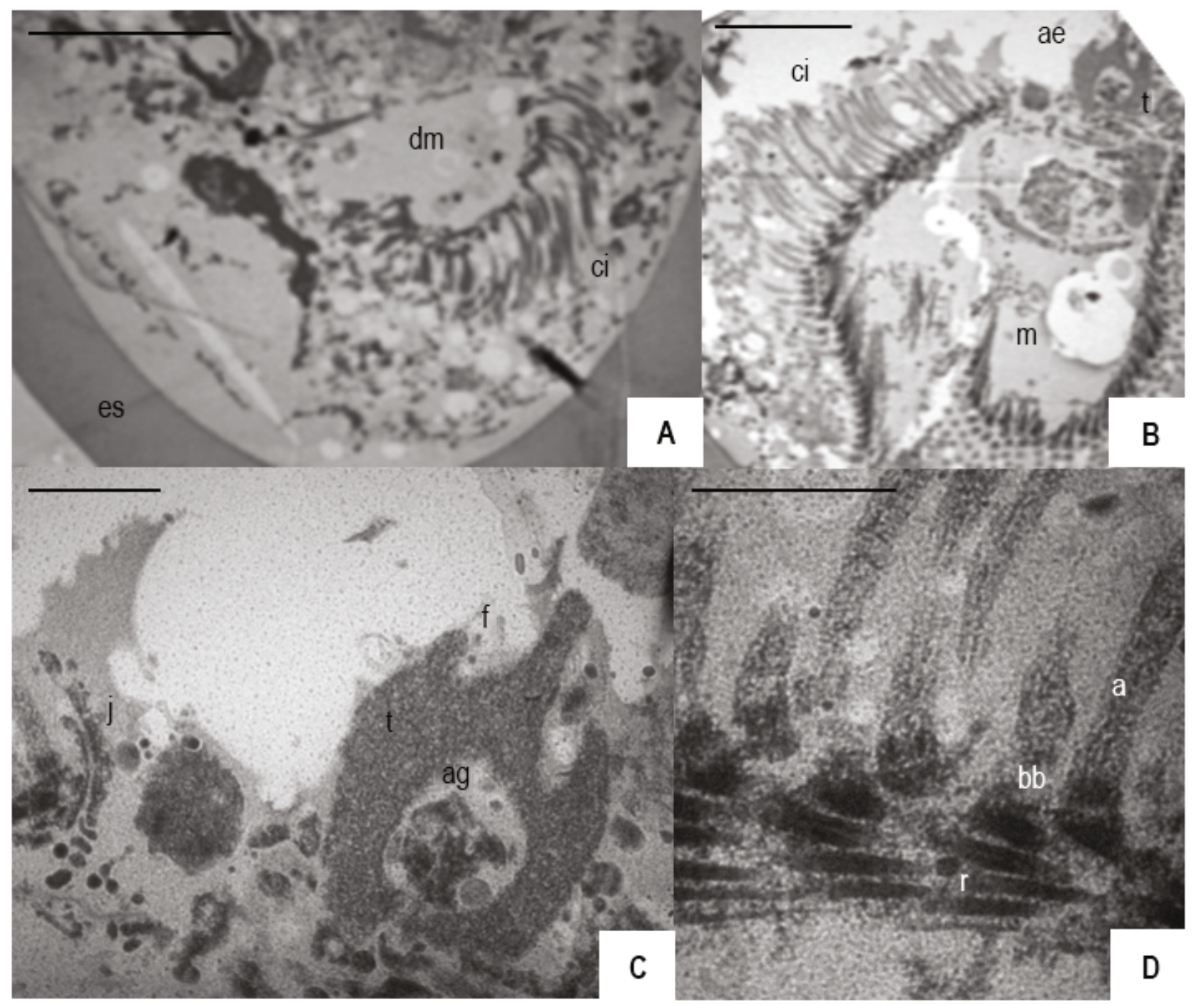

Fig. 4. TEM of miracidium of Eurytrema coelomaticum. a - Egg processed by routine technique, showing the eggshell (es) and one degenerated miracidium (dm) inside it. Scale bar $=5 \mu \mathrm{m} ; \mathrm{b}-$ One miracidium $(\mathrm{m})$ partially preserved using the high pressure-freeze substitution technique, with the cilia (c) covering the larval body and the anterior end $(a e)$ well defined with the terebratorium $(t)$. Scale bar=5 $\mu \mathrm{m} ; \mathrm{c}-\mathrm{A}$ detailed view of the terebratorium region $(\mathrm{t})$ with foldings $(\mathrm{f})$, and the junction $(\mathrm{j})$ between the one anterior ciliated epidermal cell and the miracidial body. Scale bar=1 $\mu \mathrm{m} . \mathrm{d}-\mathrm{A}$ detail of the cilia in the ciliated epidermal cell, with the root ( $r$ ) in a $90^{\circ}$ degree angle, basal body (bb) and the axis (a). Scale bar $=500 \mathrm{~nm}$

precursor material of the eggshell, so that in older articles the Mehlis gland was referred to as the "eggshell gland". However, most of the material from the eggshell is produced by the vitelline cells. In some species, the Mehlis gland produces two distinct types of secretions: membranous bodies and mucoid dense bodies. The membranous bodies are aggregated around the egg, as a mold for the vitelline cells, while mucoid dense bodies act to mediate the coalescence of vitelline cells for eggshell formation (Bogitsh, 1987). According to Cordingley (1987), the stabilization of structural proteins like sclerotin and keratin to give rigidity to the eggshell occurs by crosslinking of adjacent chains of amino acids to proteins. Most digenetic trematodes' eggs appear to achieve stabilization by a process of quinone tanning, where the eggshell becomes hard and brownish.

Although the observation of isolated eggs is more useful in studies of morphology and morphometry, the observation of grouped eggs provides more insight into the natural condition in which these eggs are found in nature. The dimensions of the eggs measured in the present study are different from those reported by Tang (1950), who observed length and width of 46 and $32 \mu \mathrm{m}$, respectively, for E. pancreaticum eggs. This is an important result, since the taxonomy of Eurytrema species is confused, especially in relation to the species $E$. coelomaticum and E. pancreaticum. This difference in the egg size reported here, with the E. pancreaticum eggs being larger than $E$. coelomaticum eggs, constitutes a new feature, not described until now, that can help in the correct identification of both species, reinforcing the data reported by Zheng et al. (2007) using molecular biology techniques.

Also, this is the first report of the ultrastructure of the eggshell, which is thicker in the anterior and posterior ends and thinner in the middle/lateral region. Also, there are no specializations such as the knob described at the posterior end of the eggshell in Echinostoma paraensei (Pinheiro et al., 2004a; b). This characteristic has not been shown before. The operculum region was first viewed 
using SEM and TEM, and by LM, it was possible to observe its detachment and the early exit of the miracidium from the egg. The previous published study on the morphology of $E$. coelomaticum (Tang and Tang, 1977) only contained drawings or figures, with little definition and details of the eggs, opercula and their aperture. The miracidia of some trematodes, such as Schostosoma mansoni and Fasciola hepatica, have been widely studied (Pan, 1980; Mueleman, 1972), but the miracidium of $E$. coelomaticum was only roughly described by Tang and Tang (1977), with no description of the larva. For the first time, images of the E. coelomaticum miracidium are presented here obtained by LM and TEM, revealing details of the miracidium body and structure. The present study reveals detailed morphology of $E$. coelomaticum miracidium, including the terebratorium region in different moments, showing the variation in the shape of this structure, which led Tang and Tang (1977) to describe the presence of a stylet in the anterior region of the terebratorium. Here we observed that this "stylet" was in reality the interepidermal ridge between the two epidermal ciliated cells in the anterior row. The precise moment of the miracidium emerging from the egg was also shown, with aperture of the operculum. Also, the excretory and reproductive systems were observed and some details of these structures corroborated the information initially described by Tang and Tang (1977). The silver nitrate impregnation showed the epidermal ciliated cells. The miracidium body is covered by four ciliated epidermal plates (cells) arranged in two rows of two cells each, and the exact position of them is described according to the nomenclature of Dimitrov et al. (1995). The variation in the miracidial shape observed in the figures presented here corroborates the findings of Pinheiro et al. (2004), who using TEM observed longitudinal and circular musculatures in the miracidial body, allowing contractions in both directions and resulting in an elongated or pear shape of the larvae, depending on the contraction status. An important observation in the present study is the interepidermal ridge of the anterior row, which in the previous published report (Tang and Tang, 1977) was called a stylet because it appeared to be an artifact to those authors. Using TEM, it was possible observe details of the terebratorium region, revealing folds, as well as the apical gland inside it and the junction of the anterior epidermal cell and the miracidium body. Further studies observe well preserved larvae will be needed to determine the ultrastructural details, such as reproductive and excretory system, as well as the tegument. This study brings new information on the procedures to obtain better images using the HPFS technique, to overcome the eggshell barrier in the fixing and embedding procedures.

The present study provides important details of $E$. coelomaticum morphology, obtained by using different techniques, which together improve understanding of this trematode. It is somewhat difficult to discuss our results due the lack of data about the morphology of this parasite in the current literature. Since 1977, this is the first morphological study on the eggs and larvae (miracidia) of $E$. coelomaticum and the first using different techniques to observe this parasite. The absence of information of a widespread trematode that causes substantial losses to cattle breeders points to the need for more studies of this species. So, this is basically the first report on the morphology of eggs and miracidia and corrects some mistaken information. However, complementary studies are needed to obtain more detailed information, not only for a better understanding of the morphology, but also the biology of $E$. coelomaticum, mainly the eggs and miracidia. Studies are particularly necessary to determine eggshell composition of mature and immature eggs by using SEM and TEM X-ray microanalysis, as well as NMR and mass spectrometry. Also, better characterization of the ciliary system organization in the miracidium by comparing it to that of ciliated protozoa would be welcome. Finally, SEM and TEM analyses of fragments of host snail tissues should be done to reveal the interaction between the larval stages and host. Therefore, the present study is the basis for further studies to improve the knowledge of this trematode's biology, which will enable studies to develop drugs to control eurytrematosis, a cattle disease that occurs widely in the southern region of Brazil as well as in some countries in Asia, such as China and Japan.

\section{Acknowledgements}

We thank Beatriz Ferreira Ribeiro, Giovana Alves de Moraes, and Márcia Adriana da Silva, LBCT, CBB, UENF, RJ, Brazil for technical support in microscopic analyses.

\section{Financial Support}

Financial support was provided by Coordenação de Aperfeiçoamento de Pessoal de Nível Superior (CAPES), Conselho Nacional de Desenvolvimento Científico e Tecnológico (CNPq) (304532/2011-8), Fundação Carlos Chagas Filho de Amparo à Pesquisa do Estado do Rio de Janeiro (FAPERJ) (E102.304/2013) and Financiadora de Estudos e Projetos (FINEP). JP has a FAPERJ postdoctoral grant and JP, RAD and WS are CNPq research fellows.

\section{References}

Amato, J.F.R., Boeger, W., Amato, S.B. (1991): Protocolos para laboratório: coleta e processamento de parasitos de pescado. Rio de Janeiro: Imprensa Universitária, UFRRJ. 81p.

Bassani, C.A., Sangioni, L.A., Saut, J.P.E., Yamamura, M.H., HeadLEY, S.A. (2006): Epidemiology of eurytrematosis (Eurytrema spp. Trematoda: Dicrocoeliidae) in slaughtered beef cattle from the central west region of the State of Paraná, Brazil. Vet. Parasitol., 141: 356 - 361. DOI:10.1016/j.vetpar.2006.06.003

BoGITSH, B.J. (1987): Further observations on eggshell formation in Haematoloechus medioplexus (Trematoda, Digenea). Trans. Am. Microsc. Soc., 106: 373 - 378. DOI: 10.2307/3226229

Brandolini, S.V.P.B., Amato, S.B. (2001): Desenvolvimento de Eurytrema coelomaticum (Giard et Billet) (Digenea, Dicrocoeliidae) em Bradybaena similaris (Fèrussac) (Gastropoda, Xanthonychidae). Rev. Bras. Zool., 18: 499 - 502

CoRdingleY, J.S. (1987): Trematode eggshells: novel protein biopolymers. Parasitol. Today, 3: 341 - 344. DOI: 10.1016/01694758(87)90118-9

De SouzA, W. (2007): Técnicas de Microscopia Eletrônica Aplicada as Ciências Biológicas. Sociedade Brasileira de Microscopia, Rio de Janeiro, RJ. 657p. 
Dimitrov, V., Kanev, I., Fried, B., Radev, V. (1995): Argentophilic structures of miracidia of Echinostoma trivolvis (Cort, 1914) (Trematoda: Echinostomatidae). J. Parasitol., 81: $306-307$

Franco-Acuña, D.O., Pinheiro, J., Oliveira-Menezes, A., Brandolini, S.V.P.B., DAMATTA, R.A., DE SouZA, W. (2011): Light and scanning electron microscopy of sporocysts of Eurytrema coelomaticum (Giard et Billet, 1892) Looss, 1907. Vet. Parasitol., 177: 72 - 78. DOI: 10.1016/j.vetpar.2010.11.038

Girard-Dias, W., Alcântara, C.L., Cunha-e-Silva, N., de Souza, W., MIRANDA, K. (2012): On the ultrastructural organization of Trypanosoma cruzi using cryopreparation methods and electron tomography. Histochem. Cell. Biol., 138: 821 - 831. DOI: 10.1007/s00418012-1002-8

GiaRd, A., Billet, A. (1892): Sur quelques Trématodes parasitesdes boeufs du Tonkin. C. R. Soc. Biol., 94: 613

Humason, G.L. (1979): Animal tissue techniques. W. H. Freeman and Company, CA, USA. 661p.

ILHA, M.R.S., LoRettI, A.P., ReIS, A.C.F. (2005): Wasting and mortality in beef cattle parasitized by Eurytrema coelomaticum in the State of Paraná, Southern Brazil. Vet. Parasitol., 133: 49 - 60. DOI: 10.1016/j.vetpar.2005.02.013

IRWIN, S.W.B., Threadgold, L.T. (1972): Electron-microscope studies of Fasciola hepatica. X. Egg formation. Exp. Parasitol., 31: 321 - 331. DOI: 10.1016/0014-4894(72)90093-8

KARNOVSKY, M.J. (1965): A formaldehyde-glutaraldehyde fixative of high osmolarity for use electron microscopy. J. Cell. Biol., 27: 137 KoIE, M. (1971): On the histochemistry and ultrastructure of the tegument and associated structures of the cercariae of Zoogonoides viviparous in the first intermediate host. Ophelia, 9: $165-206$ Meuleman, E.A., Holzmann, P.J., Peet, R.C. (1980): The development of daughter sporocysts inside the mother sporocyst of Schistosoma mansoni with special reference to the ultrastructure of the body wall. Z. Parasitenkd., 61: $201-212$

PAN, S.C. (1980): The fine structure of the miracidium of Schistosoma mansoni. J. Invert. Pathol., 36: 307 - 372. DOI: 10.1016/00222011(80)90040-3

Pinheiro, J., Franco-Acuña, D.O., Oliveira-Menezes, A., Brandolini, S.V.P.B., De SouzA, W., DaMatTA, R.A. (2011): Ultrastructure of the sporocysts of Eurytrema coelomaticum (Giard et Billet, 1892) Looss, 1907. Vet. Parasitol., 182: 201 - 212. DOl:10.1016/j.vetpar.2011.05.044

Pinheiro, J., Maldonado, A., Attias, M., Lanfredi, R.M. (2004a): Ultrastructure of the miracidium of Echinostoma paraensei Lie and Basch, 1967 (Trematoda, Echinostomatidae). Parasitol. Res., 97: 367 - 372. DOI: $10.1007 /$ s00436-005-1458-8

Pinheiro, J., Maldonado, A., Attias, M., Lanfredi, R.M. (2004b): Light and scanning electron microscopy of the miracidium of Echinostoma paraensei (Lie and Basch, 1967) (Trematoda, Echinostomatidae). Vet. Parasitol., 26: 265 - 275. DOl:10.1016/j.vetpar.2004.02.019

Pinheiro, J., Franco-Acuña, D.O., Oliveira-Menezes, A., Brandolini, S.V.P.B., De Souza, W., DaMatTa, R.A. (2011): Ultrastructure of the sporocysts of Eurytrema coelomaticum (Giard et Billet, 1892) Looss, 1907. Vet. Parasitol., 182: 201 - 212. DOI: 10.1016/j.vetpar.2011.05.044

Race, G.J., Martin, J.H., Moore, D.V., LaRSH, J.E. (1971): Scanning and transmission electron microscopy of Schistosoma mansoni eggs, cercariae and adults. Am. J. Trop. Med. Hyg., 20: 914 - 924. TANG, C.C. (1950): Studies on the life history of Eurytrema pancreaticum Janson, 1889. J. Parasitol., 36: 559 - 574

TANG, Z., TANG, C.C. (1977): The biology and epidemiology of Eurytrema coelomaticum (Giard et Billet, 1892) and Eurytrema pancreaticum (Janson, 1889) in cattle and sheep in China. Acta Zool. Sinica, 23: $267-282$.

Travassos, L. (1944): Revisão da família Dicrocoeliidae, Odhner, 1910. illus. Monographias do Instituto Oswaldo Cruz, Instituto Oswaldo Cruz, RJ. 357 p.

WILSON, R.A. (1967): The structure and permeability of the shell and vitelline membrane of the egg of Fasciola hepatica. Parasitology, 57: 47 - 58. DOI: 10.1017/S0031182000071882

Yamaguti, S. (1971): Synopsis of Digenetic Trematodes of Vertebrates. Keigaku Publishing, Tokyo, Vol. 1.

Zheng, Y., Luo, X., Jing, Z., Hu, Z., CAl, X. (2007): Comparison of $18 S$ ribosomal RNA gene sequences of Eurytrema coelmaticum and Eurytrema pancreaticum. Parasitol. Res., 100: 645 - 646. DOI: 10.1007/s00436-006-0281-1 